\title{
EI Intelectual y el compromiso religioso en una sociedad democrática
}

José M. . González Ruíz

Antes de nada convendría hacer una descripción de lo que podemos entender por "intelectual". Julien Benda ${ }^{1}$ lo describe tomando como punto de comparación al Estado. En efecto, a lo largo de veinte siglos hemos visto a los que habían predicado al mundo que el Estado debe ser justo, que de pronto se ponen a proclamar que el Estado debe ser fuerte, llegando a burlarse de las pretensiones de ser justo. Es lo que ocurrió con el famoso asunto Dreyfus.

Esta actitud ya viene de muy antiguo. En el Gorgias de Platón Sócrates le replica así al "realista":

"Tú exaltas en la persona de los Temístocles, de los Cimón. de los Pericles, a hombres que han tratado a cuerpo de rey a sus conciudadanos sirviéndoles todo lo que deseaban, sin preocuparse de enseñarles lo que es bueno y honesto en materia de alimentación. "Han engrandecido al Estado", exclaman los atenienses; pero no ven que este engrandecimiento no es más que una hinchazón, un tumor lleno de corrupción. He aqui todo lo que han hecho esos antiguos políticos para tener llena la ciudad de puertos, de arsenales, de murallas, de tributos y otras fruslerias, sin añadir a todo ello la templaza y la justicia".

Y es que para Sócrates, perfecto modelo del intelectual fiel a su esencia, las murallas son "fruslerias"; lo serio es la justicia y la templanza. Pero para los que hoy ocupan un determinado cargo, la justicia es lo que es una fruslería; las cosas serias son los arsenales y las murallas.

Además, un moralista moderno, como Sorel, ha aprobado sin rebozo a los jueces que, en su calidad de buenos guardianes de los intereses de la tierra, condenaron a Sócrates, cosa que no habíamos visto todavía desde aquella tarde en que Critón cerró los ojos de su maestro.

Benda subraya que los intelectuales modernos han predicado que el Estado debe ser fuerte y que hay que burlarse de que sea justo; $y$, en efecto, han dado a esta afirmación un carácter de predicación y de enseffanza moral. Cuando Maquiavelo aconseja el tipo de acciones que ya sabemos, no les confiere a estas acciones ninguna moralidad, ninguna belleza. Maquiavelo es tremendamente coherente consigo mismo: a la moral la llama moral, y a la eficacia eficacia. Por eso dice con un sano cinismo que

(1) La trahison des clercs, Paris 1977, pp. 248 ss. 
es inútil llevar a la política preocupaciones o escrúpulos éticos. Por el contrario, los intelectuales de ayer que han accedido a puestos de gobierno no se resignan a perder la aureola de su status anterior y pretenden sacralizar la propia fortaleza disimulándola con afeites democráticos.

\section{Intelighentsia e intelectuales}

Pero para comprender mejor el contenido del oficio de intelectual, es necesario atender a la diferencia que Alvin W. Gouldner ${ }^{2}$ establece entre la "intelighentsia" cuyos intereses son fundamentalmente "técnicos" y los "intelectuales", cuyos intereses son primordialmente críticos, emancipadores, hermeneúticos y, por lo tanto, casi siempre políticos, aunque sólo sea indirectamente.

La "intelighentsia" técnica se concentra en las operaciones realizadas dentro del paradigma (o los paradigmas) de su disciplina, explorando su espacio simbólico interno, extendiendo sus principios a nuevos campos y afinándolo. Los intelectuales, en cambio, son aquéllos cuyos campos de actividad carecen, por lo común, de paradigmas consensualmente convalidados, pueden tener varios paradigmas rivales y, por tanto, no toman la ciencia normal, con su único paradigma dominante, como caso habitual. Los intelectuales transgreden con frecuencia las fronteras de la división convencional del trabajo en la vida intelectual; sin embargo, no rechazan la erudición, sino la normalización de la erudición.

Parece que a los auténticos revolucionarios habria que reclutarlos entre los intelectuales puros. El mismo Gouldner ${ }^{3}$ advierte que el carácter mandarinesco de los revolucionarios comenzó con los mismos Marx y Engels y con los hegelianos de izquierda de la que aquéllos provenian. Los hegelianos de izquierda eran sabios de clase media, quienes, subraya Goran Therbon", eran típicamente "no bohemios"; en otras palabras, burgueses. ¿Quién podía haber sido más burgués que Marx, que interrogaba tiránicamente a los pretendientes de sus hijas, para exigirles seguridades de que no las tendrían en la miseria en que él las había criado? ¿Y quién más mandarín que el Marx que se sabía a Goethe de memoria, leía a Esquilo en el original, cuya admiración por Shakespeare era ilimitada, leía dos o tres novelas al mismo tiempo, y que hasta escribió un "Cálculo infinitesimal"?

Marx y el marxismo son creaciones de una "intelighentsia" académica que frecuenta bibliotecas, ramonea por las librerías y ama los museos y, por lo tanto, dispone de ocio suficiente.

Alvin Gouldner ${ }^{5}$ reconoce que el nuevo modelo de intelectualidad encarnado en el marxismo ha sido un fracaso histórico. En efecto, el Manifiesto comunista afirmaba que la historia de todas las sociedades que han existido hasta ahora era la historia de la

(2) El futuro de los intelectuales y el ascenso de la nueva clase, Madrid 1980, pp. $71 \mathrm{~s}$.

(3) 0. cit.p. 81.

(4) Science, Class and Society, Londres 1976.

(5) o. cil., p. 123. 
lucha de clases: hombres libres y esclavos, patricios y plebeyos, señores y siervos, maestros gremiales y oficiales, y, luego, burguesía y proletariado. Pero en esta serie había una regularidad no explícita: los esclavos no sucedieron a los amos, los plebeyos no vencieron a los patricios, los siervos no derrocaron a los sefiores, los oficiales no triunfaron sobre los maestros. La clase baja nunca llegó al poder. Tampoco parece probable que ocurra ahora.

\section{El Profeta}

Ahora descendemos ya al terreno propiamente religioso, donde el intelectual adquiere el nombre específico de "profeta". Bertrand Russell" reconoce que en muchos países, con el avance de la civilización, los sacerdotes se separan cada vez más del resto de la población y se hacen cada vez más poderosos. Pero como guardianes de la tradición antigua son conservadores, y como poseedores de las riquezas y del poder tienden a hacerse hostiles o indiferentes a la religión personal. Más pronto o más tarde todo su sistema es derribado por los seguidores de un profeta revolucionario. Buda, Cristo y Mahoma son los ejemplos más importantes históricamente. El poder de sus discípulos era al principio revolucionario y sólo gradualmente se hizo tradicional. En ese proceso absorvieron generalmente gran parte de la vieja tradición que habían destruído nominalmente.

Sin embargo, hay que reconocer, con el mismo Engels, que la vena profética del cristianismo, aunque fue seriamente amenazada por la intrusión del poder y del dinero en las filas de los seguidores de Jesús, nunca desapareció del todo a lo largo de la historia de la Iglesia. Es cierta la observación de Russell, pero no podemos olvidar que la historia se escribe desde el poder, y que, por eso, nos son desconocidos muchos avatares de la vida cotidiana que sólo relucen cuando se investiga en los archivos ocultos. Un ejemplo podrá esclarecer lo que estamos diciendo. Nadie niega la triste historia de la Inquisición española; pero, para limitarnos solamente a la época clásica, observamos que si los verdugos de aquella institución pertenecían a la Iglesia católica, también eran miembros de ella sus principales víctimas. Y son precisamente éstas las que han sobrevivido al olvido y son recordadas bajo los ilustres nombres de Teresa de Jesús, Juan de la Cruz, Luís de León, Bartolomé de Carranza, Juan de Avila y tantos otros que se perdieron en el anonimato.

\section{Profeta en democracia}

Los que hemos vivido y padecido la larga noche de una dictadura y la negación o notable disminución de las libertades no podemos echar las campanas al vuelo porque ahora nos hallemos en una democracia. Parecería como si a una Iglesia profética que en el tardofranquismo jugó un papel importante en la lucha por la libertad y la democracia

(6) El poder en los hombres y en los pueblos. Buenos Aires 1968, pp. 43 ss. 
habría que agradecerle los servicios prestados y licenciarla de su profesión profética. En efecto, si ya existen las libertades, ¿qué tiene que hacer una Iglesia levantando una voz que ya no se necesita, supuesto que el nuevo sistema funciona perfectamente? Sin embargo, la cosa no es tan sencilla. Yo diría que una sociedad democrática necesita aún más de la denuncia profética. Y esto por varias razones.

1.") Porque una democracia, por definición, se presenta como justa y equitativa. Aquí viene al caso la citada observación de Julien Benda: Maquiavelo presentaba el paradigma de un Estado que claramente prescindía de la ética y se refugiaba sólo en la eficacia. Podríamos decir que se trata de un cinismo honesto. Es algo parecido a lo que se dice en el Evangelio: "A quien diga una palabra contra el hijo del hombre, le será perdonada; pero al que hable contra el Espíritu Santo, no le será perdonado ni en este tiempo ni en el que venga" (Mt 12,32). "Pecar contra el hijo del hombre" es llamarle a las cosas por su nombre; se trata del que reconoce su culpa y la considera como tal. Por el contrario, "pecar contra el Espíritu" es presentar el pecado como si fuera virtud.

Una situación que oficialmente se presenta como de libertad y de plenitud difícilmente está preparada para recibir las amonestaciones de unos sedicentes profetas que se considera que ya han cumplido su misión satisfactoriamente en la anterior situación de falta de derechos y libertades. Sin embargo, los cristianos siempre creemos que el poder es un espacio de tentación, ya que de suyo es el Estado el que desconecta al que lo detenta con respecto a la masa sobre la que ejerce su mandato.

2.) Porque inexorablemente una democracia da paso a la competitividad por encima del valer. Y así el sistema electoral, sobre todo según la ley $D$ 'Hont, tiene el grave peligro de marginar a las minorías, no sólo sociales, sino incluso políticas. En efecto, en todo proceso electoral hay siempre unos vencidos, algunos de los cuales son recogidos por las computadoras, pero otros muchos escapan a todo control. El Estado democrático no deja por eso de convertirse en una máquina devoradora de individuos y de grupos humanos.

Y esto es tanto más peligroso cuanto que la actual situación tecnológica hace del propio sistema democrático una especie de aprendiz de brujo que no puede dar marcha atrás a ciertos procesos que se iniciaron por la fuerza objetiva de la gran maquinaria en la que se ve fatalmente envuelta toda clase de poder, tanto de derecha como de izquierda, lo mismo del occidente como del este. La tecnificación robotiza a todos los estamentos de la sociedad, y al mismo régimen democrático se le escapa de las manos el dominio de sus propios instrumentos. $Y$ así vemos ciertos grupos políticos que, cuando actuaban en la oposición ofrecían un programa ideal, y que al tomar el poder dan un giro de ciento ochenta grados, sin que esto signifique un mero cambio cínico de ideas, sino una necesidad objetiva, imperiosamente exigida por las inexorables leyes de una política que se ha deshumanizado para tecnificarse por completo.

3.") La tercera razón de la actualidad de una denuncia profética en una sociedad democrática es que hoy, como ayer Constantino, el nuevo poder ha comprendido que el anticlericalismo no es políticamente rentable. No podemos olvidar que Constantino fue, por así decirlo, un emperador de izquierda. Es decir: comprendió que el paganismo no tenía futuro para seguir siendo una ideología legítimadora del imperio, mientras que el cristianismo se presentaba ya como un bloque compacto y robusto, dispuesto a asumir la pesada herencia de las viejas religiones del imperio. Es muy difícil convencerse de 
que Constantino fuera un creyente cristiano sincero. En todo caso su sinceridad se limitaba a reconocer honestamente la utilidad del cristianismo para una nueva y más vigorosa legitimación de un poder que de alguna manera empezaba ya a cuartearse.

Con esto no queremos decir que el nuevo poder democrítico sueñe con una estrepitosa conversión al cristianismo. Más bien se perfila lo contrario. Eso sí, ha comprendido perfectamente que en el juego político hay que tener en cuenta la baza religiosa para encasillarla en su debido puesto y para que no produzca sobresaltos inesperados ni por falta de más ni por falta de menos.

Haciendo unas modestas quinielas podemos sospechar que la democracia intentará con todas sus fuerzas establecer firmes pactos con la cumbre eclesiástica y que, al mismo tiempo, no verá con buenos ojos que grupos de militantes cristianos se sitúen a su izquierda, reproduciendo la antigua situación periclitada de la dictadura, cuando ambos iban cogidos del brazo clamando por la libertad denegada. Esto producirá, sin duda, algunas fricciones, hasta hoy no tipificadas, entre grupos cristianos de base y las nuevas autoridades salidas de unas umas democráticas. $Y$ así se dará el caso, impensable hasta hace poco, de que el poder civil democrático y las jerarquías eclesiásticas podrán estar de acuerdo en reprimir o suprimir manifestaciones de militantes cristianos o de grupos eclesiales de base. Y se cumple una vez más el viejo refrán italiano: "Lupo non mangia lupo": los lobos no se comen entre sí.

\section{Un paradigma: la teología de la liberación}

Un modelo de compromiso religioso en la sociedad democrática lo tenemos en la llamada "teología de la liberación", sobre todo tal como se desarrolla en América Latina. Y para no salimos de nuestro tema hemos de considerar que todos los acontecimientos que se desarrollan en el subcontinente americano dependen muy estrechamente de la que se considera democracia paradigmática de los Estados Unidos de Norteamérica.

Para enfocar el problema, veamos cómo son tres las circunstancias que hay que considerar: los acontecimientos políticos que forman el cuadro y hacen de fondo; el ambiente cultural con las teorías que de alguna manera han servido de base y de soporte, el clima eclesial, los hechos religiosos más notables, especialmente el fenómeno de las comunidades eclesiales de base (CEB), que ha sido y sigue siendo el humus dentro del cual brota y crece la "teología de la liberación".

Después de siglos de dependencia colonial con respecto a Europa, América Latina a partir de la primera guerra mundial y en forma cada vez más acelerada después del segundo conflicto internacional, pasó a ser controlada por el poderoso vecino del Norte: los USA tomaron el puesto de una Europa ya decadente, especialmente de Inglaterra, conquistando una posición económica y política de privilegio definitiva. $Y$ así en estos últimos treinta años en América Latina tanto los intelectuales como las masas populares han ido tomando, día tras día, afio tras año, conciencia de la trágica situación de subdesarrollo y miseria, que constituyen el caldo de cultivo de continuos sobresaltos violentos de revoluciones y contrarrevoluciones, en una dramática altemancia de optimismo y pesimismo. 
Hay que reconocer que desde un punto de vista cultural ha sido en las universidades donde se han echado las bases de la teología de la liberación ${ }^{7}$. En ellas grupos cristianos, cada vez más numerosos, se comprometen políticamente por la liberación del subcontinente americano. Estudiantes y profesores, inicialmente por antigua tradición, tenían un margen de libertad en el interior de su institución, por la que podían regirse y gobernarse en plena autonomía. En este contexto estudiantes cristianos y teólogos, comprometidos con ellos, empezaron a madurar una nueva consciencia de que la condición de subdesarrollo, de retraso, se debía a una injusticia estructural. $Y$ así el subdesarrollo, en esta perspectiva, se debería a la supervivencia de instituciones arcaicas y a la escasez de capital en zonas que se han quedado aisladas del flujo de la historia mundial.

Y de este modo la Iglesia, que poco a poco se apropiaba de este análisis, empezó a denunciar proféticamente abusos, injusticias y las excesivas desigualdades y a comprometerse en un esfuerzo de educación de las clases pobres y marginadas, de forma que no solamente se convertía en voz de los que no tenían voz, sino que procuraba que se restituyera la palabra a aquéllos que desde siglos carecían de ella: al pueblo pobre y culturalmente menos evolucionado. En este último compromiso ha tenido un notable influjo la pedagogía del brasileño Paulo Freire: su método de alfabetización y conscientización, cuyo impacto revolucionario es indudable, ha sido usado por obispos, sacerdotes, agentes de pastoral, de suerte que al final evangelización y conscientización se han convertido en realidades indisolubles.

Así se comprende que el famoso "informe Rockefeller" hablara de la Iglesia como de "una fuerza comprometida en el cambio, llegando a la revolución, si es necesario", e invitaba a prestar la máxima atención a este hecho. También el estudio de los investigadores de la "Rand Corporation" para el Departamento de Estado USA había tenido por objeto "al clero como elemento de cambio social en América Latina"; y más tarde el "informe de Santa Fe" para el presidente Reagan ha reafirmado que "la política exterior americana debe empezar a luchar contra la teología de la liberación, como se utiliza en América Latina por el clero de la teologia de la liberación. El papel de la Iglesia en América Latina es vital para el concepto de libertad política. Desgraciadamente las fuerzas marxistas-leninistas han utilizado a la Iglesia como arma política contra la propiedad privada y el capitalismo productivo, haciendo que en la comunidad religiosa se infiltraran ideas comunistas más que cristianas".

El hecho de que la gran democracia del norte hubiera acusado recibo del indudable golpe que le inflingía la más alta intelectualidad cristiana, que era nada más y nada menos que la teológica, explica que en el propio Vaticano sonaran fuertes las señales de alarma. Norteamérica había tocado la tecla sensible del peligro de contagio marxista, que pudiera implicar a la teología de la liberación. Todo esto explica la reacción que se produce en la curia romana, donde la custodia de la fe está encomendada a un prestigioso teólogo alemán, Joseph Ratzinger, y donde la suprema instancia se encarna en un hombre que ha sufrido en sus carnes el zarpazo del comunismo soviético importado

(7) Cfr., JUAN LUIS SEGUNDO. Les deux théologies de la libération en Amérique Latine, en "Etudes", setiembre 1984. 
por la fuerza a una nación que le debe a la tradición católica su misma identidad náacional.

El conflicto ha saltado a la opinión mundial y ha tomado dimensiones gigantescas demostrando con ello que en este mundo occidental, que tanto se precia de la libertad y de la democracia, todavía tienen un sitio holgado y necesario los viejos profetas cristianos. A pesar de los enormes recelos que al cardenal Ratzinger le despertaba la teología de la liberación, en la recentísima reunión que en el propio Vaticano ha tenido con un grupo de obispos brasileños - los más significativos de toda esta campaña-, la teología de la liberación ha salido modernamente reforzada en la "Instrucción sobre libertad cristiana y liberación", emanada el 22 de marzo de 1986 por la misma Congregación para la Doctrina de la Fe.

En primer lugar, en la Instrucción se admite expresamente la tesis fundamental de la teología de la liberación, según la cual los pobres no son sólo objetos de la reflexión teológica, sino sujetos de ella: "Son los pobres, objeto de la predilección divina, quienes comprenden mejor y como por instinto que la liberación más radical, que es la liberación del pecado y de la muerte, se ha cumplido por medio de la muerte y resurrección de Crisio" (n. 22). Por eso, "es una noble tarea eclesial que atañe al teólogo, ayudar a que la fe del pueblo se exprese con claridad y se traduzca en la vida, mediante la meditación en profundidad del plan de salvación, tal como se desarrolla en relación con la Virgen del Magnificat" (n. 98).

En segundo lugar, la teología de la liberación confiesa que su ámbito vital lo constituyen las comunidades eclesiales de base. A este respecto se afirma: "Las nuevas comunidades eclesiales de base y otros grupos cristianos formados para ser testigos de este amor evangélico son motivo de gran esperanza para la Iglesia" (n. 69). Eso sí, con tal de que vivan "en comunión con la Iglesia local y con la Iglesia universal" (ibid.). Así, pues "una reflexión desarrollada a partir de una experiencia particular, puede constituir un aporte muy positivo, ya que permite poner en evidencia algunos aspectos de la Palabra de Dios, cuya riqueza total no ha sido aún plenamente percibida" (n. 70). Esto confirma la reiteración con que los latinoamericanos insisten en sostener que su teología no es exportable.

Cada ámbito eclesial debe forjar su propia reflexión teológica, siguiendo las exigencias de la inculturación (n.9 96).

Otra novedad agradable de la Instrucción es la adopción del lema básico en la teología de la liberación: "La opción preferencial por los pobres, lejos de ser un signo de particularismo o sectarismo, manifiesta la universalidad del ser y de la misión de la Iglesia" (n. 68). Eso sí, dicha opción no es exclusiva" (ibid.).

Sin embargo, la carga profética de la teología de la liberación encuentra todavía algunos recelos en el vértice vaticano. $Y$ así en la Instrucción, cuyos aspectos positivos quedan firmes, se notan algunas ambigüedades o lagunas, que serán los mismos teólogos los llamados a resolver o colmar.

$Y$ así, en efecto, presenta un aspecto demasiado apologético, cuando rechaza como inexistente el hecho histórico de que "su constitución jerárquica estaría opuesta a la igualdad; su Magisterio estaría opuesto a la libertad de pensamiento" (n. 20). Con esto se olvida que en tiempos recientes el mismo Magisterio romano condenaba como funesta nada menos que la liberzad de expresión. En la Instrucción se alude a estos 
errorès, pero se insinúa que los responsables de ellos serian "los cristianos" (ibid.), siendo así que lo fue el propio Magisterio pontificio.

Además, en la Instrucción se afirma con razón que el hombre, "queriéndose liberar de Dios, se extravia y se destruye; se autoaliena" (n. 37), pero se olvida reconocer, con la Gaudium et spes, que en este rechazo de Dios han sido frecuentemente los cristianos los verdaderos responsables, porque "en vez de revelar, velaron el verdadero rostro de Dios". Esto quiere decir que la denuncia de la actitud inmanentista y autosuficiente del hombre contemporáneo sólo puede ser hecha por una Iglesia que ofrezca al mundo una fe límpida y humilde en el verdadero Dios de Jesús.

Finalmente, los teólogos de la liberación manejan mucho el tema del Exodo, y a este respecto la Instrucción advierte que "si Dios saca a su pueblo de una dura esclavitud económica, política y cultural, es con miras'a hacer de él, mediante la alianza en el Sinal, un reino de sacerdotes y una nación santa". Por consiguiente, el acontecimiento mayor y fundamental del Exodo tiene un significado a la vez peligroso y político" (n. 44). Esta referencia se expone a una interpretación "espiritualista" del Exodo, como si a Dios sólo le interesara la liberación de su pueblo en función de una dimensión religiosa, siendo así que está claro que Yavé se mueve primordialmente por su amor desinteresado a un pueblo oprimido.

\section{Conclusión}

En una sociedad democrática el intelectual cristiano debe, en primer lugar, desenmascarar la trampa saducea de un sistema que a priori y por definición se presenta justificado por sí mismo. Hoy se habla mucho de ética del poder, pero ello puede esconder la mala conciencia de los antiguos luchadores contra el poder dictatorial de una situación anterior. El intelectual cristiano debe seguir el consejo de Benda: no pertenecer a ningún partido político, para verse más libre en su tarea de denunciador de las irregularidades éticas que indudablemente comete el poder por más democrático y popular que se presente.

Pero, en segundo lugar, el intelectual comprometido debe tener dos virtudes fundamentales. La primera es la limpidez de su vida: que en realidad se crea lo que dice y que esté dispuesto a darlo todo por ello. Los cristianos acuñaron la palabra "mártir" para indicar que el auténtico testigo de un mensaje no puede reducirse a ser meramente un transmisor, sino que debe estar dispuesto a dar la vida por él.

La segunda virtud es la humildad: una denuncia auténticamente profética no se puede hacer desde el borrascoso torbellino de una cátedra definitoria y condenatoria, sino desde la humildad del que anda de puntillas, toca el hombro de su hermano y le ofrece con carifio y respeto algo que él mismo considera esencial para el bienestar y la salvación de la humanidad. Pablo de Tarso - y con esto termino-, prototipo del intelectual cristiano comprometido definía así su presentación del mensaje cristiano en la culta y rica ciudad griega de Corinto: "Yo, hermanos, cuando llegué a vosotros, no llegué anunciándoos el misterio de Dios con el prestigio de la palabra o de la sabiduría; pues me propuse no saber entre vosotros otra cosa que Jesucristo, y éste crucificado. Y me presenté ante vosotros débil, acomplejado y temblando mucho. Mi palabra 
y mi predicación no consistian en hábiles discursos filosóficos, sino en demostración de espíritu y de fuerza, de suerte que vuestra fe se basa no en sabiduría de hombres, sino en fuerza de Dios" (I Cor 2, 1-5). 